\title{
The O'Hearns: Estate Planning In The Presence Of Long-Term Care Considerations
}

David O’Bryan, (Email: obryan@ @ittstate.edu), Pittsburg State University Jeffrey J. Quirin, (Email: jeffrey.quirin@wichita.edu), Wichita State University Rebekah Sheely Heath, (Email: rheath@ @ittstate.edu), Pittsburg State University

\begin{abstract}
This case exposes students to issues surrounding estate planning when one or both spouses contemplate a need for costly long-term care. The role of Medicare and especially Medicaid in paying for such care is emphasized. The case addresses such issues as whether or not to purchase long-term care insurance and what factors to consider when transferring assets. In addition to addressing legal and technical issues, the case also addresses ethical issues (e.g., the ethics of impoverishing oneself through the transfer of assets in order to qualify for Medicaid). It may be used in any undergraduate or graduate level course that includes some emphasis on estate planning.
\end{abstract}

\section{Introduction}

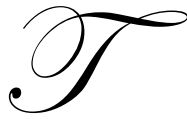

his case exposes students to the complexity of estate planning for the middle class. Estate planning issues which typically focus on avoiding the probate process and/or minimizing the impact of gift and estate taxes are issues affecting primarily the wealthy. However, when one or both spouses anticipate a need for long-term care, estate planning for middle class individuals becomes equally complex. Students will approach these issues by assuming the role of an advisor to a family with an ailing father, healthy but aging mother, and two adult sons. The parent's assets which include a family home and rental real estate total $\$ 400,000$ - too little to have to pay federal estate tax but not enough to provide long-term coverage for the father and potentially the mother at a future date.

The learning objectives this instructional case is designed to achieve are: (1) to help students understand the role of a will, a living will, durable health care power of attorney and general durable power of attorney in the estate planning process, (2) to allow students to determine the application of the federal gift and estate tax law to a specific case, (3) to help students understand how the transfer of assets to a trust may aid in avoiding estate taxes but may create problems when applying for Medicaid, (4) to understand the role of long-term care insurance and be able to identify key factors in the purchase of such a policy, (5) to distinguish between Medicare Part A, Medicare Part B, and Medicaid, and (6) to understand the general guidelines for qualifying for Medicaid, especially with respect to asset transfers.

\section{Case}

\subsection{Background}

John and Mary O'Hearn have a relatively modest estate valued at approximately $\$ 400,000$, the details of which are summarized in Table 1. Although they had never given much thought to estate planning, John's recent health problems have prompted them to seek your advice. They present you with the following facts related to their situation. 
John is 70 and his health is declining. About five years ago he had quadruple bypass surgery. Since then he has developed adult onset diabetes and high blood pressure. Several years ago he had a mild stroke and recently had another, slightly more severe stroke. His doctors have given him the grim, but true, reality of strokes - the general pattern is for them to recur and become progressively worse. Another stroke can strike without much warning and be devastating. A serious stroke can leave a person unable to care for themselves. Furthermore, a person may live in this state for years.

In stark contrast, John's wife, Mary, is 68 and the picture of health. She has had virtually no health problems and is very active. The only concern for her health is the physical and psychological impact of caring for an ill spouse.

John and Mary have been married nearly 45 years and neither has been divorced. They have two sons, Jack and Don. The parents have the utmost trust in both Jack and Don. Both sons are married, with children of their own, and financially stable. Jack and Don trust each other and have never had any serious disagreements. Neither expects to receive anything from their parents' estate. They just want to make sure their parents won't suffer financial hardship during their retirement years.

\subsection{The Need For Estate Planning With Long-Term Care Considerations}

Since they have no wills, John and Mary have recently consulted an attorney. She told them they needed a will, a living will, a durable health care power of attorney, and a general durable power of attorney. In their will, it is John and Mary's desire that the first spouse leave their entire estate to the surviving spouse. When the surviving spouse dies any remainder is to be divided equally among their two sons. The attorney is drafting these documents and has recommended they sign them as soon as possible. The only exception is the general durable power of attorney. She counsels they wait to sign it until "you're unable to take care of your own affairs" since this document could allow your designated agent to "rob you blind and leave you penniless."

The thought of eventually having to go to a nursing home is depressing to both John and Mary. Both are accustomed to active lives and are fiercely independent. Consequently, it was difficult for them when the attorney also recommended they think about how they would pay for long-term care if it should become necessary. In their area, long-term care is currently costing about $\$ 60,000$ per year. This does not include prescription drugs, which can easily add another $\$ 4,000$ per year and, in many cases, much more. She recommended they each buy a longterm care insurance policy to help cover these potential costs.

John and Mary are each covered by Medicare Part A and Part B. ${ }^{1}$ They have no prescription drug coverage beyond that provided by Medicare and they have no long-term care insurance. After the meeting with their attorney they did consult with a long-term care insurance representative. He informed them that a $\$ 100$ per day lifetime policy for Mary would cost about $\$ 1,500$ per year. Due to John's health history, a similar policy was not available for him. The best policy the company would offer John was a $\$ 100$ per day benefit with a $\$ 20,000$ lifetime maximum benefit at a cost of nearly $\$ 1,800$ per year. The O'Hearns have no experience with long-term care insurance and can only trust that their sales representative is offering them a good product at a reasonable cost given their health histories.

\subsection{The Role Of Medicaid And Living Trusts In Estate Planning For The Middle-Class}

John and Mary have also heard things from their friends. They know that many people in nursing homes are covered by Medicaid. ${ }^{2}$ In fact, several close acquaintances are on Medicaid and have suggested it is "the only way to go." To be covered by Medicaid a person must be impoverished. Medicaid then covers medical costs including the cost of long-term care.

\footnotetext{
${ }^{1}$ Qualification for Medicare is based on attaining age 65 and being eligible for Social Security benefits. Part A which covers inpatient hospital expenses is automatic, while Part B which covers outpatient health-care expenses is optional.

2 About $70 \%$ of nursing home patients are on Medicaid (Medicaid for Millionaires, 2005).
} 
They also know that many people establish living trusts as part of their estate planning. John and Mary wonder if they could transfer their property to a trust and then qualify for Medicaid. Alternatively, they have contemplated transferring their assets directly to their sons so that they could qualify for Medicaid. John is reluctant to do this because he knows there are tax advantages to transferring property at death rather than while still living. Plus, their sons are both in higher income tax brackets which would reduce the after-tax return on their rental properties. John and Mary also need their monthly rental income to supplement their income from social security. Finally, a wealthy friend told John not to forget about the effect of gift and estate taxes.

All of this information has left John and Mary confused and bewildered. Estate planning is not something either of them wants to do. Having to deal with John's deteriorating health and these financial concerns at the same time is even more difficult. They desperately need your help.

Table 1

John and Mary O'Hearn's Assets and Income

\begin{tabular}{|c|c|c|c|}
\hline Assets & Cost & & $\begin{array}{c}\text { Estimated } \\
\text { Market Value }\end{array}$ \\
\hline Cash & $\$ 15,000$ & & $\$ 15,000$ \\
\hline Personal Property, Including Vehicles & $\$ 30,000$ & & $\$ 20,000$ \\
\hline House & $\$ 25,000$ & & $\$ 75,000$ \\
\hline Real Estate (same county of residence) & $\$ 160,000$ & & $\$ 200,000$ \\
\hline Real Estate (out of state) & $\$ 15,000$ & & $\$ 25,000$ \\
\hline $401 \mathrm{~K}-$ Mary & $\$ 15,000$ & & $\$ 15,000$ \\
\hline Life Insurance - John (face value) & $\mathrm{n} / \mathrm{a}$ & & $\$ 20,000$ \\
\hline Life Insurance - Mary (face value) & $\mathrm{n} / \mathrm{a}$ & & $\$ 30,000$ \\
\hline Total Assets & & & $\$ 400,000$ \\
\hline Monthly Income & John & Mary & Joint \\
\hline Social Security & $\$ 1,000$ & $\$ 500$ & \\
\hline 401K Distribution & & $\$ 100$ & \\
\hline Rental Income - Rental House & & & $\$ 400$ \\
\hline Rental Income - Commercial Building & & & $\$ 500$ \\
\hline Miscellaneous (e.g., Interest) & & & $\$ 100$ \\
\hline Total Monthly Income & $\$ 1,000$ & $\$ 600$ & $\$ 1,000$ \\
\hline
\end{tabular}

\section{Discussion questions}

1. What is the role of each document (i.e., will, living will, durable health care power of attorney, and general durable power of attorney) recommended by the attorney?

2. Should John and Mary sign their general durable power of attorney now or follow their lawyer's advice and wait until they are incapacitated?

3. Should John and Mary be concerned about gift and estate taxes? Why or why not?

4. Will a trust help John and Mary with their estate planning problems? Explain.

5. Should John and Mary buy long-term care insurance? What are the key factors they should look for in a long-term care policy?

6. Distinguish between Medicare Part A, Medicare Part B, and Medicaid. 
7. What are the general guidelines to qualify for Medicaid? If one spouse is severely ill but the other spouse is healthy can the ill spouse qualify for Medicaid without impoverishing the healthy spouse?

8. What factors should John and Mary consider if they are contemplating transferring their assets to their sons so that they will qualify for Medicaid?

\section{Teaching Notes}

\subsection{Overview}

This case may be used in any undergraduate or graduate level course that includes some emphasis on estate planning. Most estate planning strategies focus on avoiding the probate process and/or minimizing the impact of federal gift and estate taxes. This case discusses those topics, but also exposes students to the issues surrounding estate planning for the middle-class when one or both spouses contemplate a need for long-term care. Some common estate planning tools that are very effective at avoiding probate or minimizing gift and estate tax may not provide any benefits for a person with significant, long-term, health care obligations.

As future advisors to elderly clients or their families, accounting students would benefit from some exposure to estate planning issues in conjunction with long-term care considerations. Today's financial planners face a "dual exposure" as (1) the client base (i.e., the baby boom generation) ages and (2) the baby boomers' parents age. This generation is often referred to as the "sandwich generation" because they have dependent children at home as well as dependent elderly parents. This makes financial planning all the more complicated.

In addition to addressing planning issues, this case could also be used to illustrate an ethical dilemma. Transferring assets to qualify for Medicaid is a controversial, but legal, process. In 1997, Congress passed a law making it illegal for paid advisors to assist clients in transferring their assets to qualify for Medicaid (Fried, 1997). That law was later deemed unconstitutional, but has never been formally repealed. The current status of the law highlights the controversy underlying this topic (Carter, 1998). Although this is not intended to be the central issue in the case, an instructor could use this case to spark a debate over an advisor's role in controversial, but legal, processes.

\subsection{Suggested Solutions}

1) What is the role of each document (i.e., will, living will, durable health care power of attorney, and general durable power of attorney) recommended by the attorney?

A will takes effect upon death and provides for the distribution of the deceased person's probate estate. This process is overseen by a probate court to ensure the estate is distributed according to the terms specified in the will. There are two main disadvantages to probate. First, it is a public process and the probate estate is part of the public record. This is undesirable for those seeking to keep their estates confidential. Second, the probate process can be costly with fees ranging from two to five percent of the probate estate (Christensen, 2001). Despite these disadvantages, a will is highly desirable. In the absence of a will, state law will govern how the probate estate is distributed and these laws may be inconsistent with the wishes of the deceased.

It is important to note that some assets do not pass through probate. The most common exceptions are real estate held as joint tenants with the right of survivorship, payable on death accounts, and contracts (e.g., life insurance, $401 \mathrm{~K}$ plans) with named beneficiaries. These mechanisms are simple and inexpensive ways to avoid the disadvantages of the probate process.

Assets that have been transferred to a trust (revocable or irrevocable) also avoid probate. In fact, probate avoidance is usually the primary reason for establishing a living trust. However, creating a trust and transferring the assets into the trust can cost several thousand dollars or more. Consequently, a trust may be impractical for small estates. 
A living will and a durable health care power of attorney are two types of so-called advance directives. The durable health care power of attorney, or health care proxy, specifies someone to make health care decisions for you if you are unable to do so for yourself. A living will allows you to state the kind of health care you want, or do not want, if you are incapacitated. For example, living wills allow a person to state whether they want a "do not resuscitate", or DNR, order on their health care chart. A person may also specify whether he wants extraordinary means taken to keep himself alive (e.g., feeding tube) if he is clinically brain dead. Although a person may have either advance directive without the other, most advise having both since they tend to reinforce either. The living will states the specific health care decisions to be made for the circumstances that were foreseen. The durable health care power of attorney then appoints an agent to make any health care decisions not specifically addressed by the living will.

A general durable power of attorney allows you to designate a person to conduct business transactions on your behalf if you are unable to do so for yourself. Great caution is urged with a durable power of attorney because the designated person has the authority to enter contracts, buy or sell real estate, open or close accounts, and do anything that you would have been able to do for yourself. In the hands of a dishonest person, a general durable power of attorney is very dangerous. However, if a person becomes incapacitated without a general durable power of attorney his or her estate is frozen. A court must then appoint a conservator and the court must oversee and approve the actions of the conservator, including such items as paying monthly bills.

2) Should John and Mary sign their general durable power of attorney now or follow their lawyer's advice and wait until they are incapacitated?

The lawyer's advice was based on the premise that no matter whom you name as your general durable power of attorney, people change and circumstances change. A trusted person could encounter personal or financial hardship that might cause them to no longer be a good candidate for your general durable power of attorney. In John and Mary's case, they were going to name each other as their primary agents with a son as the secondary agent if the spouse was unable to serve. This still leaves open the possibility that John and Mary might later divorce or have a disagreement with their son. Events such as these argue for signing your general durable power of attorney only when you can no longer conduct your own affairs.

There is a major disadvantage to not signing this document earlier though. If a person suffers an immediate and severe health problem, such as a major stroke, it may leave them mentally or physically unable to sign the document. And, if the document is not signed, it is useless. If one has a history of health problems leading a reasonable person to conclude there is a high likelihood he or she could have an immediate and serious health crisis, then serious consideration should be given to signing this document before it is too late.

Alternatively, John and Mary might sign a "springing" durable power of attorney which would not go into effect until one or the other was judged to be incompetent. With this type of power of attorney it is critical that individuals specify "precisely what flips the switch" (Greene, 2004). For example, the O'Hearns' attorney could prepare the power of attorney subject to a disability which means one or both of the sons would gain control only if a doctor was willing to certify, under penalty of perjury, that John or Mary was incapable of handling his or her own affairs.

3) Should John and Mary be concerned about gift and estate taxes? Why or why not?

Under the current U.S. tax rules, John and Mary do not need to be concerned about gift and estate taxes. For 2006 through 2008, a person may gift while living, or distribute from their estate, up to $\$ 2$ million ( $\$ 3.5$ million in 2009) without incurring any gift or estate taxes ${ }^{3}$. Unless John or Mary experience a significant change in their financial position (e.g., inheritance, lottery winning) their estate is significantly below the exclusion for gift and estate taxes.

\footnotetext{
${ }^{3}$ Internal Revenue Code, Sec. B (11) (A) (II) § 2631(c), as amended by P.L. 107-16
} 
4) Will a trust help John and Mary with their estate planning problems? Explain.

A trust may be either revocable, meaning its grantors can later change it, or irrevocable, meaning they may not make subsequent changes. In either case, a trust would help John and Mary avoid the probate process. If they want their estates to remain confidential and avoid the cost of probate then they may decide to spend a few thousand dollars now to avoid probate in the future.

Although gift and estate taxes are not an issue for John and Mary, the instructor may wish to point out that trusts are commonly used by persons with larger estates to make sure they do not lose their $\$ 2$ million exemption. For example, if John and Mary each had a $\$ 2$ million estate and their wills merely left their estate to the surviving spouse then the last spouse to die would have a $\$ 4$ million estate, a \$2 million exemption (in 2006), and \$2 million subject to gift and estate tax. Alternatively, had John and Mary each transferred $\$ 2$ million to a trust, the entire estate would have passed to their heirs without incurring any gift or estate tax.

A key point to stress with this case is that most estate planning strategies focus on probate avoidance and/or minimization of gift and estate taxes. If John and Mary are primarily interested in Medicaid planning then a revocable living trust will not help them accomplish their goal. Medicaid treats assets held in revocable living trusts as part of the applicant's assets since the grantor/applicant still has the discretion to change the trust and access the trust assets. In contrast, an irrevocable trust can help John and Mary qualify for Medicaid since the assets will have been irreversibly transferred out of their name. However, any assets transferred to an irrevocable trust within five years of applying for Medicaid will be included in the applicant's estate for purposes of qualifying for Medicaid. Consequently, this alternative will only help them if they do not contemplate needing Medicaid for at least five years after they create and fund the irrevocable trust.

John and Mary might also benefit from a primary residence transfer with a retained life estate. Usually a Medicaid applicant's primary residence is an exempt asset that will not prevent the applicant from qualifying for Medicaid. However, once the applicant and spouse are no longer expected to return home, a lien can be placed on the residence to reimburse the government for expenses paid on the applicant's behalf. John could transfer the house solely into Mary's name, which exempts it from the five-year ineligibility period. After John had begun to receive Medicaid benefits, Mary would then transfer the ownership interest to the sons, retaining an exclusive lifetime interest to live in the home. By retaining a life interest, the family home is no longer subject to the aforementioned lien, because the life estate would expire at Mary's death. Furthermore, the sons are deemed to have inherited the property for tax purposes which affords them date-of-death value as their basis in the home for income tax purposes. This strategy is not without pitfalls, however. For example, if the family decides after these transfers that current real estate market conditions dictate a sale of the premises during Mary's life, negative tax consequences may result (Davidoff, 2003).

5) Should John and Mary buy long-term care insurance? What are the key factors they should look for in a long-term care policy?

This note will strive to provide the reader with a brief overview of the key features of most long-term care insurance policies. Long-term care insurance policies are complicated and a thorough explanation of all policy terms and conditions is beyond the scope of this teaching note.

When purchasing long-term care insurance there are four main considerations. First, what is the daily benefit? This is the maximum amount you will receive from the insurance company on a daily basis for your care. You can usually select between $\$ 50$ and $\$ 250$ per day of coverage. Determine the current cost of care in your area, or the area in which you contemplate going for long-term care, and it will help you decide what daily benefit you want. A lower daily benefit will reduce the cost of the policy. For an additional charge, the daily benefit may be indexed to rise with inflation. If you are younger and/or in excellent health when you buy the policy, then you should seriously consider this option since nursing home costs may rise dramatically by the time you need long-term care. 
The second consideration is the benefit period. This is the length of time you will receive payments from the insurance company once you need care. You usually can select a specific number of years or lifetime plans are also available. The average length of stay in a nursing home is two and one-half to three years, but this is just an average. A shorter benefit period will reduce the cost of the policy.

Third, the deductible associated with a long-term care policy is stated as the elimination period. This is the number of days that you will be responsible for paying for your care before the insurance begins to pay. Most plans have a variety of options like zero days, 20 days, 60 days, or 100 days. A longer elimination period should reduce the cost of the policy. The policy should also state whether this is a once in a lifetime deductible or if it is repeated for each re-entry to the nursing home.

The last consideration is whether the policy provides any benefits for care in your home or at an assisted living facility. This option provides you with more flexibility and may allow you to remain in your own home rather than going to a nursing home. This option will typically increase the cost of your policy.

Mary appears to be in an excellent position to buy long-term care insurance. She is 68 and has no major health problems. The policy quoted to her in the case has a lifetime benefit period. She may also want to inquire about inflation protection for the daily benefit and whether any benefits are available for home health care. Although the annual cost is not insignificant, it appears to be reasonable considering the cost of long-term care. If Mary buys a policy with a lifetime benefit while she is still healthy, the premium will be more affordable and she will also have insured her estate from being depleted by the costs of long-term care. While few people want to contemplate the thought of having to go to a nursing home, long-term care insurance allows a person and their family to cope with this situation without also having to deal with the financial uncertainty of paying for this service.

John's situation is more difficult due to his poor health history. Mentally it might be very easy to compare his quote to Mary's and conclude he is being offered an inferior deal. However, John is older, as a male has a lower life expectancy than Mary, and is in poor health. In fact, it would not have been surprising if John had not been able to buy long-term care insurance at any price. Given the high likelihood that John may need long-term care, some coverage is certainly better than none at all.

It should also be noted that if long-term care insurance benefits are paid directly to the providing facility they do not adversely affect one's eligibility for Medicaid. Consequently, a long-term care policy with, say, $\$ 20,000$ in maximum benefits is effectively sheltering an equivalent amount from being depleted from your estate. In essence, for Medicaid eligibility they deem the $\$ 20,000$ as being contributed from your own resources. The purpose of this rule is to reward, or avoid penalizing, those who buy long-term care insurance.

Distinguish between Medicare Part A, Medicare Part B, and Medicaid.

Medicare Part A is the base package of health insurance available to persons age 65 or older. Most persons pay no direct charge for Part A. It is funded through the Medicare portion of the payroll tax. Part A is often referred to as hospital insurance. It covers the cost of in- patient hospital care. Part A also covers a limited amount of care in a skilled nursing home, hospice care, and some home health care services.

Medicare Part B is often referred to as medical insurance. It is a voluntary, supplemental policy which Medicare eligible persons may buy to help cover the cost of doctor's visits and outpatient hospital care. Part B also covers some medical services not covered by Part A, such as physical or occupational therapy. In addition, starting January 1, 2006, Medicare will provide some assistance with the cost of prescription drugs. For more detailed information refer to the official Medicare website at www.medicare.gov.

There is a common misperception among retirees and their family members that Medicare covers longterm care in a nursing home. Neither Part A nor Part B covers long-term health care, in-home care (unless eligible for hospice which requires a doctor's certification that a patient's condition is terminal and death is imminent), or charges for living in an independent or assisted living facility. Medicare will pay for a limited number of days in a 
skilled nursing facility following a hospital stay. ${ }^{4}$ However, for extended long-term care persons must first pay with their own resources, referred to as private pay. When their own resources are essentially depleted, they become eligible for Medicaid.

Medicaid pays medical bills for indigent persons. It covers most reasonable medical bills including longterm care. To qualify for Medicaid persons must not exceed resource limits and income limits. Resource limits refer to the applicant's financial position or net worth while income limits refer to the applicant's monthly income.

7) What are the general guidelines to qualify for Medicaid? If one spouse is severely ill but the other spouse is healthy can the ill spouse qualify for Medicaid without impoverishing the healthy spouse?

It is important to note that Medicaid is a joint Federal / state program administered by the states. Within broad Federal guidelines, each state has unique requirements. To provide an example, the following response outlines some common requirements to qualify for Medicaid for a person in a nursing home. For more specific and current information on qualifying in a particular state, visit the Medicaid website at www.hhs.gov/medicaid.

The resource limit is commonly set at $\$ 2,000$ of countable resources. Countable resources generally include all resources except a home, one vehicle, a family business, and insurance - both whole life (up to $\$ 1,500$ in cash value in New York state) and term policies. To meet the $\$ 2,000$ resource limit an applicant is allowed to prepay funeral costs into an irrevocable fund. Up to $\$ 3,500$ may be set aside for the funeral service and an unlimited amount may be allocated for merchandise, such as the casket, vault, and headstone. Additional countable resources must be spent before the applicant will qualify for Medicaid. These resources do not have to be spent on the person's healthcare, however. A person could, for example, spend their resources on travel and entertainment.

Countable resources also include all gifts made by the applicant within the past three years. It is important to note that this is completely unrelated to the gift and estate tax provisions and is intended to penalize applicants who impoverish themselves to qualify for Medicaid. For example, in 2006 up to $\$ 12,000$ may be given to any person without incurring gift tax. However, the entire $\$ 12,000$ is still included in one's countable resources for determining Medicaid eligibility. Countable resources also include the face value of life insurance policies, assets in revocable trusts, and assets transferred into irrevocable trusts within the past five years.

The home and one vehicle are termed exempt assets. In this context, exempt is somewhat of a misnomer. Exempt means the assets do not have to be liquidated to meet the resource limit. However, upon the death of the covered person Medicaid may file a lien against the exempt assets to help recover the cost of medical care provided to the deceased. ${ }^{5}$

The income limit for a person living in a nursing home is a personal needs allowance of $\$ 30$ per month. Generally, the first $\$ 30$ of a person's monthly income is allocated to the personal needs allowance and the remainder must be contributed toward the cost of their long-term care. ${ }^{6}$ Medicaid then covers any excess costs.

\footnotetext{
${ }^{4}$ Medicare provides for a maximum of 100 days of long-term nursing home care after a hospital stay of at least 3 days, provided that admission is within 30 days of hospital discharge and that the care is skilled. The first 20 days are fully covered; days 21 100 have a co-insurance amount.

${ }^{5}$ In the case of a husband and wife, the lien may not be filed until both spouses are deceased. This ensures the surviving spouse is not left homeless due to the Medicaid liability incurred by the deceased spouse.

${ }^{6}$ If a third party, such as a long-term care insurance provider, is paying all or part of the monthly fee the calculation remains the same. For example, consider a person with a $\$ 50$ per day insurance benefit, $\$ 1,000$ monthly income, and a nursing home cost of $\$ 95$ per day. The person is liable for $(\$ 1,000$ monthly income less the $\$ 30$ personal needs allowance) $\$ 970$ toward their care each month. Their insurance benefits of ( $\$ 50$ per day times 30 days) $\$ 1,500$ per month exceeds that amount so Medicaid would cover the excess monthly amount of ( $\$ 95$ per day times 30 days less the $\$ 1,500$ insurance) $\$ 1,350$. In essence, third party payments assigned directly to the nursing home are not included in the monthly income to determine the patient's own liability for care. As long as the patient, or a third party paying on behalf of the patient, contributes at least the required amount toward their care Medicaid will pay for the excess cost.
} 
Federal law provides special rules when one spouse needs long-term care but the other spouse does not. This is commonly referred to as the spousal impoverishment provisions. They are designed to provide an orderly process to split assets and income so that the well spouse is not impoverished trying to provide for the long-term care of the sick spouse. This process appears to be a likely scenario with John and Mary since Mary is in perfect health and John has a history of major health problems.

With respect to resources, in 2006, the amount of the couple's nonexempt resources which can be protected as a result of the spousal impoverishment provisions is the greater of $\$ 19,908$, or one-half of the value of the couple's nonexempt resources owned at the time the husband or wife first entered long term care, not to exceed $\$ 99,540$. Only nonexempt resources are considered. The protected resources must usually be transferred to the spouse in the community and are not considered in determining the eligibility of the person in long term care. This process is commonly referred to as the division of assets. If the well spouse subsequently applies for Medicaid he or she must meet the $\$ 2,000$ resource limitation discussed previously. Furthermore, upon the death of the second spouse Medicaid may file a lien against the exempt assets to recover the cost of providing medical care to one or both spouses.

Spousal impoverishment provisions also provide for rules to protect income for the well spouse. The amount of the couple's combined income which can be protected in 2006 is either up to $\$ 1,603.75$ per month, or up to $\$ 2,488.50$ per month if there are excess shelter expenses. ${ }^{7}$ In addition, up to $\$ 505$ per month can be protected for each dependent family member who lives with the spouse who remains at home. A dependent family member is defined as a minor or adult child, a parent, or a brother or sister of either the husband or wife who has been dependent on the couple because of legal, financial, or medical reasons. The protected income must be allocated each month to the spouse in the community and any dependent family members. The amount of this income is then exempted from consideration in determining the liability of the person in long term care for his or her cost of care.

8) What factors should John and Mary consider if they are contemplating transferring their assets to their sons so that they will qualify for Medicaid?

If John and Mary want to protect their estate from being depleted by the potentially large cost of long-term care then they may want to transfer their assets to their sons. John and Mary have the utmost trust in their sons and their sons are financially secure in their own right. Consequently, John and Mary could transfer their entire estate to their sons and subsequently be eligible for Medicaid. Their sons could, in turn, use their parent's estate to help provide for any items not covered by Medicaid or to simply ensure their parents have a comfortable retirement. As noted in the response to question seven, Medicaid only allows a covered nursing home resident $\$ 30$ per month for a personal needs allowance. The sons could supplement this amount if the parents transferred their resources to the sons rather than depleting their resources paying for long-term care. The primary Medicaid limitation is that John and Mary must wait three years from the date of transfer (i.e., the "look-back" period) to apply for Medicaid. Consequently, if they have a medical crisis prior to that they still face the risk of depleting their estate.

In summary, the easiest and most foolproof way to reduce assets without affecting Medicaid eligibility is for the individual to make gifts well in advance of the three- to five-year (for certain transfers involving trusts) lookback period. The individual should then carefully time his or her initial Medicaid application to be beyond this ineligibility period (Knoepfle, 2003). Other advisors counsel their clients to retain enough assets to be able to pay for nursing-home care for the duration of the ineligibility period (The American Bar Association, 2004, p. 205).

There are several tax considerations to transferring John and Mary's assets. One disadvantage of transferring their assets is that assets distributed at death receive a step up in basis to fair market value while assets transferred by gift while living do not. The step up in basis effectively results in no tax on the appreciation. In contrast, in 2006, the appreciation will be taxed at a maximum capital gains rate of 15 percent if transferred while

\footnotetext{
${ }^{7}$ Excess shelter costs include the total of monthly rent, mortgage payment, property taxes on the home, home insurance, and other home costs (e.g., condominium or cooperative charges) less a base allowance of $\$ 262$.
} 
John and Mary are living. ${ }^{8}$ However, an alternative way to frame this decision is to compare the maximum rate on long-term capital gains, 15 percent, to the effective tax rate of (nearly) 100 percent if they must contribute all but $\$ 2,000$ of their estate to pay for long-term care. Since John and Mary's assets have a relatively small amount of appreciation this should not be a major issue for them, but it could be for other clients.

A related tax concern is that by transferring the assets to their sons, the income produced by the assets will be taxed at the sons' marginal tax rates, which are presumably higher than John and Mary's marginal tax rate. Again, there are two ways to frame this issue. One is to compare the parent's marginal tax rate to the sons' and conclude the assets should not be transferred. The other is to compare the sons' marginal taxes to the effective tax of 100 percent if the parents must use the monthly income to pay for long-term care.

Another disadvantage of transferring their assets is what could occur if one or both of the sons had a major change in their life situation, such as a divorce or bankruptcy. Although such an event seems remote now, the future is difficult to predict. Once John and Mary have transferred their assets and gone on Medicaid they would only be left with their monthly Social Security income. From an economic standpoint they must be willing to accept the risk of something happening to their estate in the hands of their sons in exchange for the comfort of knowing that the estate will not be depleted by health care costs.

Students will hopefully raise the issue of whether it is legal or ethical to impoverish oneself to qualify for Medicaid. As long as John and Mary do not file a fraudulent application there is nothing illegal about this course of action. They may transfer all their assets to one or more persons, wait at least three years, and then apply for Medicaid. As stated previously, if the transfer is to an irrevocable trust then they must wait at least five years.

The ethical question is more difficult. John and Mary's sons are financially secure and never felt entitled to an inheritance. Some will argue that John and Mary's estate should be used to care for them during their retirement years rather than transferring that burden to the government. This is an excellent illustration of something that is legal, but questionable from an ethical perspective. Ultimately, John and Mary will have to decide how they want to distribute their estate. The role of their advisor is to help them identify their alternatives and to evaluate the costs and benefits of these alternatives. ${ }^{9}$

An alternative to transferring their resources is to simply wait until a medical crisis creates a need for Medicaid coverage. At this time, an application for Medicaid may be made in the name of the sick spouse and a division of assets and income will be made under the spousal impoverishment provisions. In the current case, John will most likely be the Medicaid applicant and Mary will be the healthy spouse remaining in the home. John would then need to spend down his portion of the allocated resources after which he would qualify for Medicaid. Mary would retain the home, one vehicle and one half of the countable resources up to the maximum of $\$ 99,540$. In addition, she would be allocated income of up to $\$ 1,603.75$ per month, or up to $\$ 2,488.3$ per month if there are excess shelter expenses.

The disadvantage of this approach is that exempt assets are not truly exempt. When the second spouse dies, Medicaid may file a lien against the house and vehicle. In addition, while Mary is in excellent health now she may also require long-term care in the future. If she does, her nursing home stay is also likely to be longer than John's because the average nursing home stay is longer for females than for males. Thus, the resources allocated to Mary may be depleted to provide for her care.

\footnotetext{
${ }^{8}$ Internal Revenue Code, Section A(1)(A)(1)§1(h)(1)(c)

${ }^{9}$ In 1996, Section 217 of the Health Insurance Portability and Accountability Act made it illegal to transfer assets to qualify for Medicaid. This section was poorly drafted and resulted in no prosecutions. Section 4734 of the Balanced Budget Act of 1997 amended this law to permit such transfers, but made it a crime to provide advice, for a fee, to any person on how to transfer assets in order to qualify for Medicaid nursing home benefits. Under this law, a paid advisor could go to jail for up to one year and be fined \$10,000 for providing such advice. In September 1998, a U.S. District Judge ruled the law unconstitutional. The Justice Department subsequently appealed this decision, but dropped the appeal in March 1999.
} 


\subsection{Closing Comments}

It should be noted in closing that John and Mary face a difficult decision. Coping with frail and deteriorating health is difficult enough by itself. Significant financial concerns can exacerbate these health problems and cause a downward spiral in the health of either or both spouses. It is important for students to understand that their financial advice can help clients minimize their frustration, stress, and confusion over these complex financial matters. This, in turn, should help the clients to focus on maintaining and improving their health so that they can continue to lead productive lives during their retirement years. In summary, students should realize that they are providing an important social service for these clients. John and Mary are not just "clients" or "billable hours", they are people that desperately need your help.

\subsection{Additional Resources}

There are a number of resources for information on long-term health-care and related issues.

- $\quad$ The Centers for Medicare and Medicaid Services maintain a website with information on Medicaid Consumer Enrollment and Coverage, Medicaid Fraud and Abuse, and Medicaid Initiatives as well as other information on the Medicaid program (www.cms.hhs.gov/home/medicaid.asp).

- $\quad$ Basic information regarding Medicaid is available at the AARP website (www.aarp.org/health/insurance/health medicaid/Medicaid the basics.html).

- $\quad$ A "Guide to Long-term Care Insurance" is available on the Health Insurance Association of America website at www.ahip.org/consumer.

- The National Citizens coalition for Nursing Home Reform offers publications, fact sheets, advocacy tips, and information on federal laws and regulations focused on nursing homes at its website (www.ncenhr.org/)

- $\quad$ The American Association of Homes and Services for the Aging (AAHSA) also has a website (www.aahsa.org/) that can provide useful information on paying for aging services.

- $\quad$ Terry W. Knoepfle's two-part article, "Medicaid eligibility rules (part I)" and "(part II)" which was published in the May 2003 and June 2003 issues of The Tax Advisor is specifically aimed at the CPA/tax advisor audience.

\section{Acknowledgements}

The third author wishes to acknowledge additional financial assistance provided by Grant Thornton, LLP.

\section{References}

1. Carter, T. (1998). Counseling Granny Now OK: Ban on advice on Medicaid asset transfers struck down. ABA Journal, November 1998, 84 A.B.A.J. 16.

2. Christensen, J. (2001). Time is right for trust services. Credit Union Magazine, Madison: March 2001, 67 (3), 93-95.

3. Davidoff, H. (2003). Elder Care and Estate Planning: Reconciling Strategies. The CPA Journal, http://www.nysscpa.org/cpajournal/2003/1203/features/f121803.htm (21 Jan. 2004).

4. $\quad$ Fried, R. (1997). Granny's Lawyer Goes to Jail. The Recorder, December 22.

5. Greene, K. (2004). Balancing Act: Giving a loved one power of attorney is an important - but risky - step. The Wall Street Journal, June 28, 5, 7 ( R ).

6. Knoepfle, T.W. (2003). Medicaid eligibility rules (part II). The Tax Advisor, June 1, 354-359.

7. . (2003). Medicaid eligibility rules (part I). The Tax Advisor, May 1, 276-282.

8. Medicaid for Millionaires. (2005). The Wall Street Journal, February 24, Eastern Edition, http://www.proquest.com/ (accessed).

9. The American Bar Association. (2004). Guide to Wills \& Estates, $2^{\text {nd }}$ edition. Random House Reference, New York: New York. 


\section{NOTES}

